in places as far apart as Ottawa and Accra, Kampala and Colombo, Kuala Lumpur and Freetown. Their research was being done at universities, institutes of agriculture and medicine, and government research laboratories, and was in subjects over a wide range, from anti-oxidants and synergists to infant weaning practices and diets. My own experience suggests that a higher proportion of nutrition graduates are actively engaged in food and nutrition research than graduates from the biomedical fields which the Committee has suggested would be more appropriate.

In the section on training for research in nutrition, there is however one useful remark, that the necessary characteristic of the nutrition specialist is that he should have a broad outlook, and that his function is to catalyse and summarise both teaching and research. Were these not the essential features in the department created by John Yudkin when he was appointed as Professor to the first school of nutrition in this country devoted to undergraduate and postgraduate teaching and research at Queen Elizabeth College at the University of London? Professor Yudkin's attitude towards nutrition was reflected in his teaching colleagues, his research students and is now shared by hundreds of nutrition graduates, working in a wide variety of fields, in many countries round the world.

It would be invidious for anyone to criticise the composition of the Committee, possessing as it did such a wealth of knowledge and experience, or to question the esteem of the co-opted members of its Working Parties. Nevertheless it remains true that only three of the fourteen members of the Committee could consider themselves as expert in human nutrition. Even more extraordinarily, neither the Committee nor the forty or more members of the Working Parties had a single representative from either of the two schools which give first degees in nutrition and which have made many notable contributions to research over the broad field of nutrition.

We in the Polytechnic at Huddersfield do not accept the views implicit in what must come to be known as the Neuberger Report. We are planning to introduce a course for the degree of MSc in Social Nutrition within a few years which will have as one of its major objectives the training of graduates from food science, nutrition, catering studies and dietetics in the social concomitants of nutrition as a preliminary to preparing them for research in this field.

Yours faithfully,

T. B. MORGAN

The Polytechnic,

Huddersfield, UK

\section{Early tunnellers}

SiR,-When I discussed early British tunnelling projects (Jan. 31, 1975) a printer's imp substituted "early 1880 s" for "early 1800s". In fact Trevithick nearly completed his LimehouseRetherhithe tunnel under the Thames scon after Waterloo and the Brunels succeeded in the 1840s. This will be found to help the sense which contrasts the preoccupation with tunnelling at the beginning of the 19th century with the switch to bridging towards the end. Angela Croome

\section{London SE3, UK}

\section{Food from allotments}

SIR, - With commendable humility, the World Food Conference in Rome called on science and research workers to bridge the gap between the incompatible elements of its action pack (Nature, 252,518 ; 1974) and I hope I have disentangled the metaphor correctly).

May I, then, suggest a tactic not considroed in Rome-one which would pay off within two years, unlike the global meteorological networks, the intensified research, the remote sensing or the testing of new technology in farmer's fields? I merely suggest that everyone who can, especially in the 'have' countries, feeds himself.

It seems plain to me that hunger cannot be alleviated by shifting money absut the world, but only by growing more food. Britain survived two wars on the produce of her allotments (over half the island's food was grown on them). If all who have consciences will devote 150 hours a year to a garden, they will do some good, unlike those who walk a few miles on one day of the ycar to collect money.

I had better explain the word 'allotment' for an international readership. In several countries, municipalities supply, at a nominal rent, small gardens (allotments) to interested citizens: "A plot of 300 square yards" (say 1/40th hectare) "should supply a family of three all year round" (Encyclopaedia Britannica, 1951, article Allotment).

There is nothing in this scheme to attract the notice of the Starvation Industry-no intercontinental jet flights, no twenty-thousand-dollar-ayear jobs, no lush research grants. So we common people must demand that land be set aside for allotments in every town. Then each of us can solve a tiny part of the problem. No more can be expected of us.

How big is the problem? I gather we need 45 million extras rations. If, then, 90 million of us-thirty million families - grow half our own food, the immediate problem is solved. With vigorous promotion, there could certainly be 30 million allotments more in the world within two years. It is no dream to pre- dict 300 million allotments, world-wide, within five years, if we try.

Those who have no land should demand it, where practical, from their local authorities.

$$
\text { F. P. Hughes }
$$

Ontario, Canada

\section{Vial body wanted?}

SiR,-It is now more than ever necessary to minimise waste in laboratories, as elsewhere. This seems to make it imperative to devise means, possibly centralised regionally or nationally, for saving and reusing vials for liquid scintillation counting. It seems that, up to the present time, almost all such vials have been discarded and destroyed after being used once only. The numbers of vials so used and destroyed annually in Britain must be very large. In this department alone, the number last year was about 100,000 .

Arguments against reusing vials are well known; the main ones are that: (1) the vials may have been irreparably damaged; (2) the vials may be irreversibly contaminated; (3) arrangements for retaining, decontaminating and washing used vials may endanger the environment and particularly, of course, the health of personnel; and (4) such arrangements are uneconomical. These arguments are valid. There are, howcver, counter-arguments, which seem to have been made unanswerable by the increasingly adverse economic and environmental conditions in which we find ourselves. The essential argument is that the destruction of once-used vials is unacceptably wasteful as the cost of producing them rises and as the materials from which they are made become shorter in supply.

I should like to propose, therefore, that a committee representing vial users, including university, research council and industrial laboratories, be set up to investigate urgently the practicability and economics of the centralised collection, storage and preparation of used vials for reutilisation. There should be little difficulty in collecting the information required for establishing quite rapidly whether this can be done economically on a regional basis. Individual laboratories should find no insuperable difficulties in collecting, storing and despatching used vials safely and efficiently.

If those who agree with this proposal and are prepared in principle to act on it would write to me, the response will be communicated to the research councils and other official organisations in the hope that action will be initiated.

Yours faithfully, G. V. R. BORN

Department of Pharmacology,

Medical School,

Hills Road, Cambridge CB2 2QD, UK 